\title{
Boundary Layer Control for Hypersonic Airbreathing Vehicles
}

\author{
Scott A. Berry, Robert J. Nowak, ${ }^{*}$ and Thomas J. Horvath ${ }^{*}$ \\ NASA Langley Research Center, Hampton, VA, 23681
}

\begin{abstract}
Active and passive methods for tripping hypersonic boundary layers have been examined in NASA Langley Research Center wind tunnels using a Hyper-X model. This investigation assessed several concepts for forcing transition, including passive discrete roughness elements and active mass addition (or blowing), in the 20-Inch Mach 6 Air and the 31-Inch Mach 10 Air Tunnels. Heat transfer distributions obtained via phosphor thermography, shock system details, and surface streamline patterns were measured on a 0.333 -scale model of the Hyper-X forebody. The comparisons between the active and passive methods for boundary layer control were conducted at test conditions that nearly match the Hyper-X nominal Mach 7 flight test-point of an angle-of-attack of 2-deg and length Reynolds number of 5.6 million. For passive roughness, the primary parametric variation was a range of trip heights within the calculated boundary layer thickness for several trip concepts. The passive roughness study resulted in a swept ramp configuration, scaled to be roughly 0.6 of the calculated boundary layer thickness, being selected for the Mach 7 flight vehicle. For the active blowing study, the manifold pressure was systematically varied (while monitoring the mass flow) for each configuration to determine the jet penetration height, with schlieren, and transition movement, with the phosphor system, for comparison to the passive results. All the blowing concepts tested, which included various rows of sonic orifices (holes), two- and three-dimensional slots, and random porosity, provided transition onset near the trip location with manifold stagnation pressures on the order of $\mathbf{4 0}$ times the model surface static pressure, which is adequate to ensure sonic jets. The present results indicate that the jet penetration height for blowing was roughly half the height required with passive roughness elements for an equivalent amount of transition movement.
\end{abstract}

\section{Nomenclature}

$\mathrm{H} \quad$ enthalpy (BTU/lbm)

h heat transfer coefficient $\left(\mathrm{lbm} / \mathrm{ft}^{2}-\mathrm{sec}\right),=\mathrm{q} /\left(\mathrm{H}_{\mathrm{aw}}-\mathrm{H}_{\mathrm{w}}\right)$ where $\mathrm{H}_{\mathrm{aw}}=\mathrm{H}_{\mathrm{t} 2}$

$h_{\mathrm{FR}} \quad$ reference coefficient using Fay-Ridell calculation at stagnation point of a sphere

$\mathrm{j} \quad$ jet penetration height (in)

$\mathrm{k} \quad$ roughness element height (in)

$\mathrm{L} \quad$ reference length of vehicle at the model scale (48.00 in)

M Mach number

m-dot mass flow rate $(\mathrm{lbm} / \mathrm{s})$

$\mathrm{P} \quad$ pressure (psi)

q heat transfer rate $\left(\mathrm{BTU} / \mathrm{ft}^{2}\right.$-sec)

$\mathrm{Re} \quad$ unit Reynolds number $(1 / \mathrm{ft})$

$\mathrm{Re}_{\mathrm{L}} \quad$ Reynolds number based on body length

$\mathrm{Re}_{\theta} \quad$ momentum thickness Reynolds number

$\mathrm{R}_{\mathrm{n}} \quad$ nose radius (in)

$\mathrm{T}$ temperature (R)

$\mathrm{x} \quad$ longitudinal distance from the nose (in)

$\mathrm{y} \quad$ lateral distance from the centerline (in)

$\mathrm{z} \quad$ height above the waterline (in)

$\alpha \quad$ model angle of attack (deg)

$\delta \quad$ boundary layer thickness (in)

\footnotetext{
*Aerospace Technologist, Aerothermodynamics Branch, m/s 408A, member AIAA. 


$\begin{array}{ll}\text { Subscripts } \\ 2 & \text { local static conditions } \\ \infty & \text { freestream static conditions } \\ \text { aw } & \text { adiabatic wall } \\ \text { cr } & \text { critical } \\ \text { e } & \text { conditions at edge of the boundary layer } \\ \text { eff } & \text { effective } \\ \text { inc } & \text { incipient } \\ \text { man } & \text { conditions within the manifold } \\ \text { t1 } & \text { reservoir conditions } \\ \text { t2 } & \text { stagnation conditions post shock } \\ \text { tr } & \text { location of transition onset } \\ \text { w } & \text { model surface }\end{array}$

\section{Introduction}

$\mathrm{T}$ HE National Aerospace Plane (NASP) program that began in the mid-80's started a renaissance in hypersonic research that culminated in the successful demonstration on March 27, 2004 of airbreathing scramjet technologies on the Hyper-X (X-43A) vehicle. Scramjet-powered vehicles, which scoop the oxygen required for fuel combustion from the atmosphere (reducing tanking and airframe requirements), have been a vision of affordable and rapid access to space for years, and now appear technically feasible. However, additional flights (another Hyper-X flight at Mach 10 is planned for late 2004) and flight-test programs (to demonstrate sustained acceleration and cruise) will be required to reach the goal of scramjet as a viable propulsion system.

Conceptually, a scramjet-powered system seems relatively simple, with no moving parts required to provide flow compression and only fuel addition and ignition needed to provide thrust. However, the feasibility of just such a system has always been tied to the details of integrating the engine to the airframe using innovative materials and structures to control the highly complex flow field while handling the high heat loads. For airframe-integrated scramjet engines, the forebody ahead of the inlet is designed to process and pre-condition the flow that will be ingested by the inlet. As shown in Fig. 1, a full-scale air-breathing vehicle will likely have competing transition mechanisms in the forebody boundary layer that will naturally force turbulent flow ahead of the inlet. Turbulent flow is desirable at the entrance to the inlet to mitigate flow separations within the engine. However, on a sub-scale vehicle such as the Hyper-X, the shorter forebody length is less likely to naturally transition prior to the engine inlet, based on the Mach 7 trajectory. The Hyper-X program decided early in the design to utilize boundary layer trips to force turbulent flow on the forebody in order to properly scale the engine flight test results to future full-scale vehicles. Reference 1 provides an overview of the experimental program that was set up to test and compare several passive trip concepts for the Mach 7 flight. (Passive is meant to imply inertness, while active denotes capability to

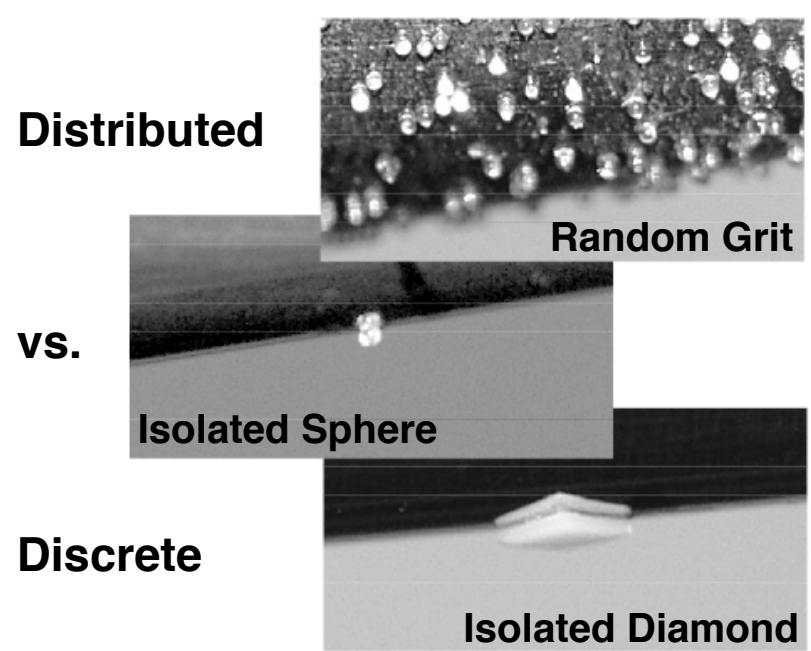

Figure 2: Classical methods for tripping boundary layers. act or react.)

A critical step in the design of hypersonic vehicles is to consider the effects of surface roughness on the boundary layer in order to determine the heating rate and integrated heat load on the vehicle for selection and sizing of the thermal protection system (TPS). Typically of interest is a determination of the various forms of roughness that can occur on the vehicle and an understanding of the critical roughness sizes that will allow as much laminar flow as possible in order to minimize the aeroheating to the vehicle. For instance, a reentry vehicle with an ablating TPS surface coating can develop a distributed and random surface roughness pattern, while a ceramic tile TPS may result in specific discrete roughness sites due to slight misalignments of the tiles forming steps and/or gaps on the surface. As depicted in Fig. 2, wind tunnel experiments are 
conducted to simulate the expected roughness for determination of the critical dimensions that will adversely affect the TPS design. For the Hyper$\mathrm{X}$ vehicle, the reverse was required: a determination of the critical dimensions that will promote hypersonic boundary layer transition in a controlled and predictable manner. A wind tunnel program was implemented to screen and downselect several passive discrete trip configurations, resulting in an array of swept ramp vortex generators, shown in Fig. 3, being chosen for the Mach 7 flight. ${ }^{1}$ More recently, tests have been

\begin{tabular}{||l|l|l|l|l|l||}
\hline Year & Tunnel & Test & Tunnel Dates & Runs & Description \\
\hline 1997 & 31-In M-10 & 338 & Aug 14 - 29 & 76 & Phosphor \\
\hline 1997 & 20-In M-6 & 6755 & Sept $2-5$ & 61 & Phosphor and schlieren \\
\hline 1997 & 31-In M-10 & 338 & Oct 1 - 20 & 94 & Phosphor and oil-flow \\
\hline 1998 & 20-In M-6 & 6768 & Apr 1 - 3 & 22 & Oil-flow \\
\hline 1998 & $31-$ In M-10 & 346 & Apr 6 - 10 & 20 & Oil-flow \\
\hline 1998 & 31-In M-10 & 349 & Sept 3 - 8 & 25 & Phosphor, final trip \\
\hline 1998 & 31-In M-10 & 351 & Sept 16 - 18 & 19 & Phosphor, closed cowl \\
\hline 1999 & HYPULSE & & Feb 23-Mar 26 & 28 & Thin-film and schlieren \\
\hline 1999 & 20-In M-6 & 6791 & Aug 10 & 10 & Phosphor, final trip \\
\hline 1999 & 20-In M-6 & 6793 & Sept 15 - 17 & 11 & Phosphor, nose roughness \\
\hline 2002 & 20-In M-6 & 6842 & July 12 - 26 & 79 & Phosphor, blowing \\
\hline 2002 & 20-In M-6 & 6847 & Dec 6 - 16 & 42 & Oil-flow, blowing \\
\hline 2003 & 31-In M-10 & 385 & Oct 22-Nov 18 & 152 & Phosphor, blowing \\
\hline
\end{tabular}

Table 1: Hyper-X trip screening tests in NASA facilities.

performed to investigate the feasibility of implementing an active method of boundary layer control via steady mass addition (blowing) for use with future applications. An active system offers the advantage of being able to tailor the amount of boundary layer control to the environment, allowing for system shut-off when not needed (although there will be a weight penalty associated with the additional system requirements). The present paper provides a status report of the results obtained to date on this exploratory investigation into using surface blowing as a tripping device for future hypersonic airbreathing vehicles.

Three new active-trip screening tests, shown in Table 1 with white background (grey corresponds to previous tunnel entries for passive roughness testing), have been completed in the Langley Research Center (LaRC) 20-Inch Mach 6 Air and 31-Inch Mach 10 Air Tunnels. The purpose of these tests was to investigate various methods for blowing on the Hyper-X forebody and to compare these results to those previously obtained for discrete roughness elements. The present study utilized the identical model and test techniques as the previous study ${ }^{1}$ that established the passive trip design for the Hyper-X Mach 7 flight vehicle. Test techniques that were utilized include phosphor thermography (provides images of the global surface heating), schlieren (provides shock details), and oil-flow (provides surface streamline information). The assembly and instrumentation for blowing was designed and built to fit within the space previously occupied by the passive trip inserts with a minimum amount of modification to the existing model. The primary parametrics in the present tests were a range of manifold pressures while monitoring the total mass flow for various blowing configurations at the nominal angle of attack $(\alpha)$ of 2-deg, a unit Reynolds number $(\mathrm{Re})$ of 2.0 million per foot, and the inlet cowl door simulated in the open position, for both facilities. The blowing configuration parametrics, which consisted of 3 basic concepts (various arrangements of holes, two and three dimensional slots, and random porosity) for providing induced vorticity within the boundary layer, were selected to provide guidelines for development of an efficient trip design for future hypersonic flight vehicles. Additional details of the previous passive roughness experimental results can be found in Refs. 2, 3, and 4. This

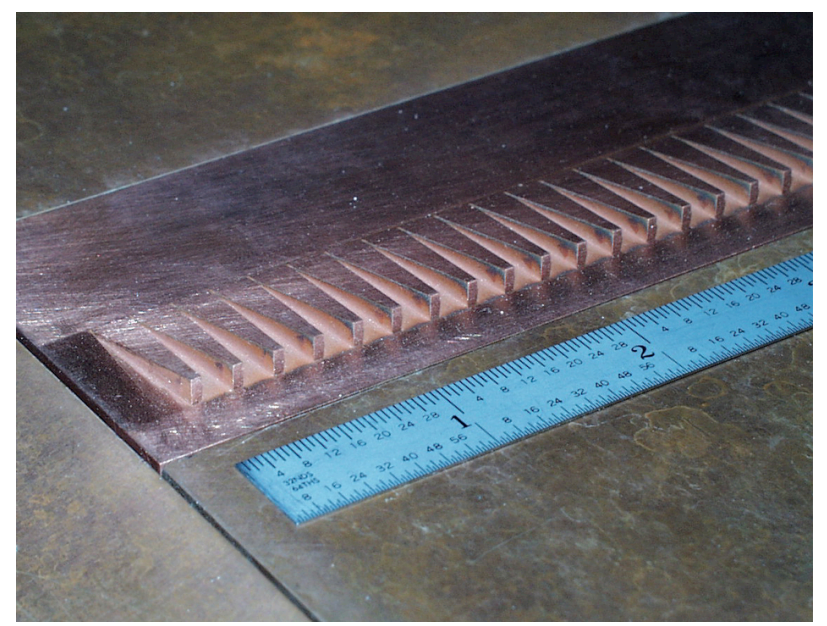

Figure 3. Close-up photograph of selected trip configuration scaled for Mach 7 flight conditions. report presents a comparison of the results from the current investigation into active methods to control the boundary layer to the earlier passive results.

\section{Hyper- $X$ and Trip Design}

The Hyper-X (X-43A) program recently completed a successful flight test of an operational airframe-integrated scramjet propulsion system at Mach 7 conditions. A second flight at Mach 10 is planned for late 2004. Additional details of this flight program can be found in Refs. 5, 6, and 7. The objective of Hyper- $\mathrm{X}$ is to obtain flight data on an autonomous hypersonic airbreathing propulsion system that is fully integrated with the vehicle airframe, thus validating/calibrating the experimental, numerical, and analytical methods that were used for design and flight performance 

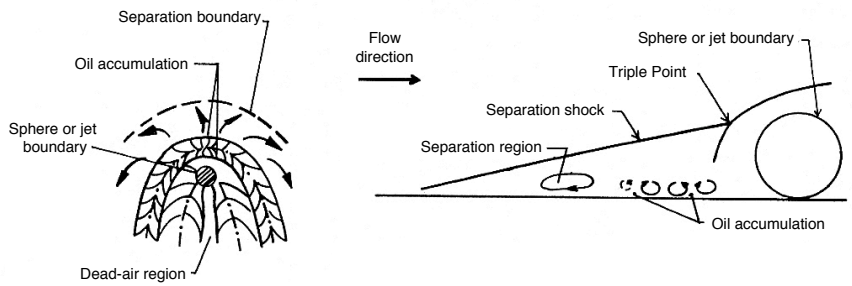

Similarities between flowfields around

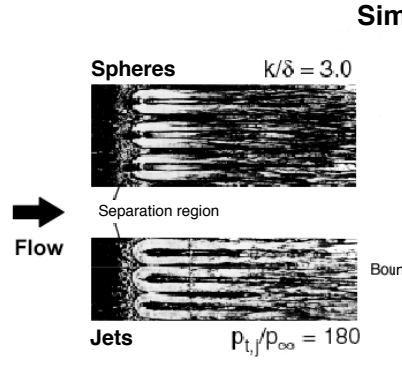
spheres and sonic jets

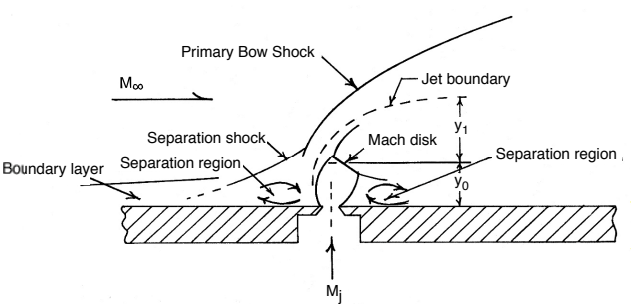

Figure 4: Previous active vs. passive trip research from Ref. 11. prediction. As with all cutting-edge flight programs, numerous technologies had to be matured to acceptable levels in order to ensure program success. One such technology was the establishment of an efficient means for control of the boundary layer on the flight vehicle. To minimize susceptibility of the scramjet engine to shock-induced flow separations, and thus engine unstarts, the boundary layer approaching the inlet should be turbulent. Based on the current knowledge of boundary layer transition for slender, planar configurations at hypersonic flight conditions, natural transition is not estimated to occur on the Hyper-X forebody, thereby requiring boundary layer trip devices to ensure a turbulent

boundary layer at the inlet for both flights (the recent Mach 7 flight data appears to confirm the necessity for trips). Figure 3 provides a photograph of the final trip configuration and size selected for the Mach 7 flight.

As part of a fully integrated scramjet propulsion system, the Hyper-X vehicle windward forebody is designed to compress and process the flow going into the inlet. The windward forebody is approximately 6- $\mathrm{ft}$ long and is characterized by a thin leading edge $\left(R_{n}=0.03-i n\right)$ and 3 flat ramps that provide a series of discrete, non-isentropic flow-compressions for the engine. While flying at the nominal angle of attack of 2-deg, the first forebody ramp provides an initial 4.5-deg of compression, followed by the second ramp with an additional 5.5-deg, and finally the third ramp with the final 3-deg of additional compression. Outboard of the flat ramps are the chines, which are designed to minimize three-dimensional effects and flow spillage. Ideally, the forebody would also provide a turbulent boundary layer for the inlet. A full-scale scramjet-powered vehicle, such as NASP or a similar derivative, would likely have sufficient forebody length to provide a naturally turbulent boundary layer. Due to the shorter forebody length of the sub-scale Hyper-X, forced boundary-layer transition is required to insure inlet operability and allow proper scaling of the engine flight test results to a future full-scale vehicle. Also, a secondary concern is whether a laminar separation at the end of the first ramp will encourage lateral spillage of the forebody boundary layer away from the inlet, potentially reducing the mass capture and affecting performance.

An analysis of the Hyper-X forebody using the hypersonic boundary layer transition criteria ${ }^{8}$ developed during the NASP program ${ }^{\dagger}$ suggests that the vehicle forebody will be fully laminar during the scramjet test period for the Mach 7 flight. The results from this analysis are detailed in Ref. 9. A boundary layer code was used to compute laminar values of $\mathrm{Re}_{\theta} / \mathrm{M}_{\mathrm{e}}$ for a sharp nose wedge with 4.5-deg compression angle. The NASP sharp planar transition criterion of $\mathrm{Re}_{\theta} / \mathrm{M}_{\mathrm{e}}=305$ was used to estimate the onset of transition. For an initial assessment, this sharp planar criterion was deemed acceptable, as nose bluntness has a stabilizing influence that would further delay transition onset. ${ }^{10}$ Based on this initial estimate, transition will not occur on the first ramp prior to the compression corner. In fact, over $200 \%$ more running length is required for transition to occur on the first ramp based on the accepted criterion, which is beyond the inlet. Thus, without some sort of flow tripping device, the potential exists for a laminar separation at the first ramp break to initiate some degree of lateral spillage. As for the question of transition prior to the inlet, the discrete compression corners will tend to promote transition, but to what extent is unclear. Very little ground based experimental data is available to provide guidance on forced transition through the use of discrete compression corners, and certainly less flight experience. To be conservative, the decision was made to force transition through the use of a passive (non-retractable) trip array on the first ramp to ensure, at the very least, turbulent flow into the inlet, and also provide some flow spillage relief at the first ramp break.

Historically, investigations into forced transition in hypersonic boundary layers typically utilized large spheres attached to the surface (as shown in Fig. 2). In fact, this method was used for most of the aerodynamic wind tunnel testing for Hyper-X. Recent work at LaRC identified the diamond configuration (also shown in Fig. 2 and referred

\footnotetext{
${ }^{\dagger}$ While much of the NASP documentation is currently still classified, the boundary layer transition criteria developed during NASP are considered unclassified. Reference 8 discusses the NASP transition database.
} 


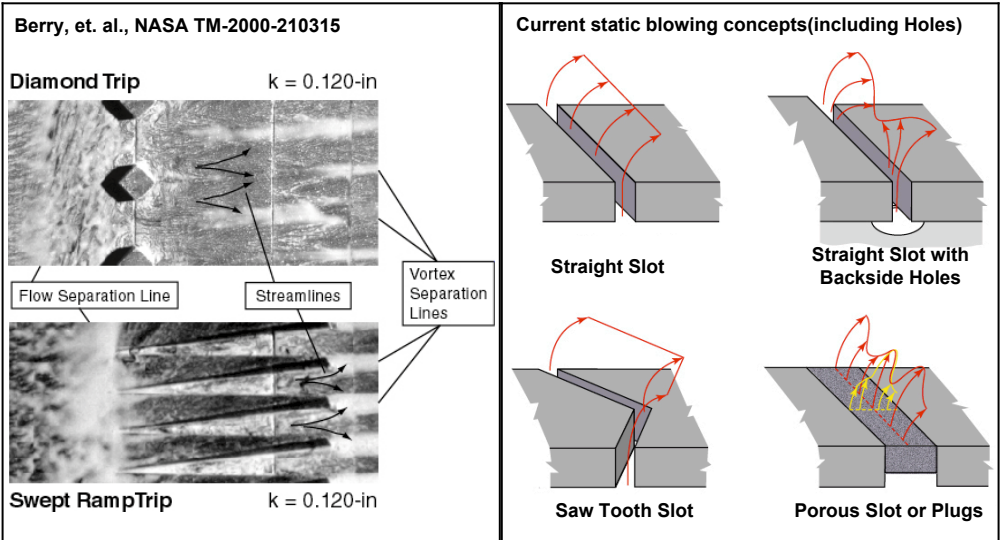

Figure 5: Current active vs. passive trip research.

to as Trip 1 in Ref. 1) as a more efficient trip mechanism than spheres. The work to define the passive trip array for the flight vehicle was an effort to further optimize the vortex generating ability of the diamond configuration, while at the same time reducing the inherent parasitic drag in order to end up with the final trip design selected (referred to as Trip 2c in Ref. 1) and shown in Fig. 3.

Sonic jets have been studied for many years for use as vehicle attitude control devices. Many of these early studies also recognized that these devices were able to induce vorticity and thus transition in the boundary layer. Reference 11 investigated discrete sonic jets as boundary layer trips and found that the tripping ability of active blowing of this type was in many ways similar to the results obtained from passive spheres, as shown in Fig. 4. In a manner analogous to the effort in Ref. 1 to improve upon the trip effectiveness of spheres, the current study attempts to re-investigate blowing as a trip mechanism to see if further improvements can be achieved. As shown in Fig. 5 for the earlier work, surface streamline directions indicate induced vorticity from the passive trip arrays. The current blowing or mass addition concepts were conceived to provide an alternative method for inducing vorticity within the boundary layer. Figure 6 provides the specific configurations tested, which includes various hole arrays, straight and saw-tooth slots, concepts utilizing porous inserts, and several backing plates designed to periodically obstruct the holes or slots. The backing plates are intended to provide for greater parametric variation in both the number of holes that are employed for any given run and to introduce three-dimensionality to the two-dimensional straight slot configuration. The current screening study of active blowing concepts for control of the boundary layer is presently compared to the previous using passive roughness results.

\section{Experimental Methods}

\section{A. Test Facilities}

The Hyper-X forebody model has been tested in both the 20-Inch Mach 6 Air and the 31-Inch Mach 10 Air Tunnels of the LaRC Aerothermodynamic Laboratory (LAL). The LAL facilities are conventional blow-down tunnels that utilize dried, heated, and filtered air as the test gas. Detailed descriptions of these facilities and their associated instrumentation are found in Refs. 12 and 13. Typical operating conditions for the LaRC 20-Inch Mach 6 Air Tunnel are stagnation pressures ranging from 30 to 500 psia, stagnation temperatures from 410 to $500^{\circ} \mathrm{F}$, and free stream unit Reynolds numbers of 0.5 to $7.8 \times 10^{6} / \mathrm{ft}$. A two-dimensional, contoured nozzle is used to provide a nominal

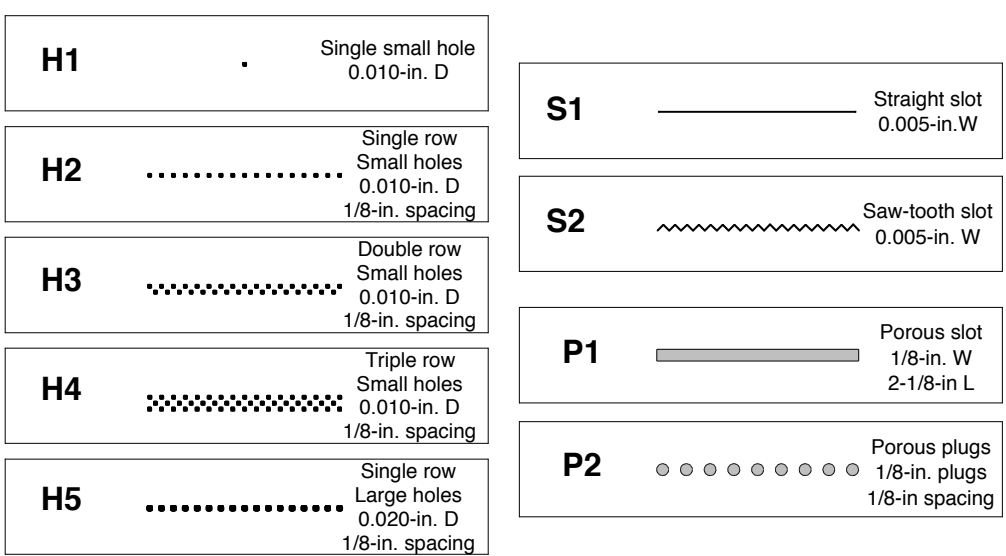

Figure 6: Configurations tested in the current research freestream Mach number of 6 . The test section is 20.5 by 20 inches. A bottom-mounted model injection system inserts models from a sheltered position to the tunnel centerline in less than 0.5 -sec. Run times of up to 15 minutes are possible with this facility, although for typical heat transfer and flow visualization tests, only a few seconds are required. Optical access to the model was viewed through a highquality window on the top of the tunnel for phosphors and oil-flow, while high-quality windows on the side provided schlieren access. Typical operating conditions for the LaRC 31Inch Mach 10 Air Tunnel are 
stagnation pressures ranging from 350 to 1450 psia and a stagnation temperature on the order of $1350^{\circ} \mathrm{F}$, which yields freestream unit Reynolds numbers of $0.5 \times 10^{6} / \mathrm{ft}$ to $2.2 \times 10^{6} / \mathrm{ft}$. The tunnel has a closed 31 - by 31 -in. test section with a contoured three-dimensional water-cooled nozzle to provide a nominal Mach number of 10. A hydraulically operated side-mounted model injection mechanism injects the model into the flow in 0.6 seconds. The maximum run time for this facility is approximately 2 minutes; however, only 5 seconds is typically required for transient heat transfer tests. Optical access to the model mechanism for both phosphors and oil-flow is viewed through high-quality top and side windows.

\section{B. Test Techniques}

A two-color, relative-intensity phosphor thermography system is currently being utilized for aeroheating tests in the LAL. References 14, 15, and 16 provide details about the phosphor thermography technique, while Refs. 17, 18, 19 , and 20 are recent examples of the application of phosphor thermography to wind tunnel testing. With this technique, ceramic wind tunnel models are fabricated and coated with phosphors that fluoresce in two regions (red and green) of the visible spectrum when illuminated with ultraviolet light. The fluorescence intensity is dependent upon the amount of incident ultraviolet light and the local surface temperature of the phosphors. By acquiring fluorescence intensity images with a color video camera of an illuminated phosphor model exposed to flow in a wind tunnel, surface temperature mappings are calculated on the portions of the model that are in the field of view of the camera. A temperature calibration of the system conducted prior to the study provides the look-up tables that are used to convert the ratio of the green and red intensity images to global temperature mappings. With temperature images acquired at different times in a wind tunnel run, global heat transfer images are computed assuming onedimensional heat conduction. The primary advantage of this technique is the global resolution of the quantitative heat transfer data. Such data can be used to identify the heating footprint of complex, three-dimensional flow phenomena (e.g., transition fronts, turbulent wedges, boundary layer vortices, etc.) that are difficult to resolve by discrete measurement techniques. Phosphor thermography is routinely used in Langley's hypersonic facilities because models can be fabricated more quickly and economically than other techniques, and the method provides quantitative global information. Recent comparisons of heat transfer measurements obtained from phosphor thermography to conventional thin-film resistance gauges measurements ${ }^{16}$ and to CFD predictions ${ }^{17,19,21,22,23}$ have shown good agreement.

Flow visualization techniques, in the form of schlieren and oil-flow, were used to complement the surface heating tests. The LaRC 20-Inch Mach 6 Air Tunnel is equipped with a pulsed white-light, Z-pattern, single-pass schlieren system with a field of view encompassing the entire 20-in test core. The LaRC 31-Inch Mach 10 Air Tunnel has recently installed a small 6-inch schlieren system. The schlieren images were recorded with a highresolution digital camera and video. Surface streamline patterns were obtained using the oil-flow technique. The metal model was spray-painted black to enhance contrast with the white-pigmented oils used to trace streamline movement. Surface streamline development was recorded with a conventional video camera, while post-run digital photographs were recorded with a high-resolution digital camera.

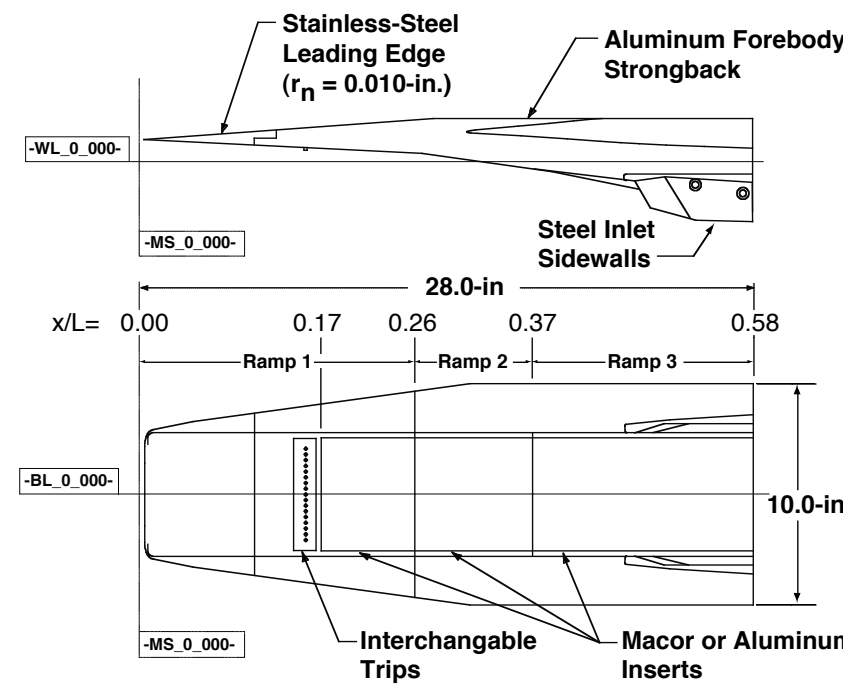

Figure 7. Hyper-X forebody model dimensions.

\section{Model Description}

A sketch of the $33 \%$ scale Hyper-X forebody model is shown in Fig. 7. Note, the chines of the forebody model were laterally truncated aft of the first ramp corner in order to minimize tunnel blockage and to isolate the model within the tunnel test core. A numerically controlled milling machine was used to build the forebody model with a detachable stainless-steel leading edge and interchangeable measurement surface inserts as well as various stainless-steel trip and inlet configurations. Although a majority of the forebody (the strongback) was constructed from aluminum to save weight, the leading edge was machined from stainless steel with a nose radius of 0.010 -in to allow replacement if damaged. The length of the leading edge was selected to be 5-in in order to provide for adequate thickness for attachment to the aluminum strongback. The trip 

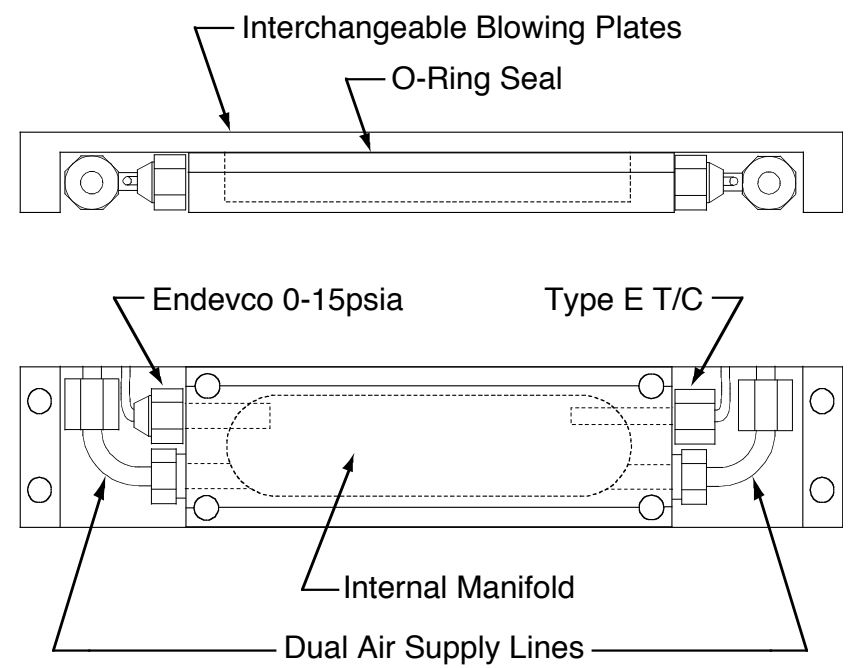

Flow Meters station was another 2.418-in aft of the leading edge attachment point (for a total length from the model leading edge of 7.418-in). The interchangeable trip configurations were designed and sized based on the local flow properties at this forebody station. The remaining flat ramp sections were designed to accommodate both Macor ${ }^{*}$ and aluminum set of inserts. The engine inlet sidewalls were made of stainless steel and were designed to accommodate both open and closed engine cowl door configurations. The open configuration represents the forebody at test point with the engine cowl door in the operating position, although for the wind tunnel model the cowl is removed to provide optical access to the internal flat ramp surface.

Normally a cast ceramic process is used to build phosphor thermography models. In this case, precision metal machining was used in lieu of the casting process as a thin high-fidelity leading edge and interchangeable trip configurations were required. As the ramp sections behind the trip location were planar across a majority of the span, 0.25-in thick flat sheets of Macor were used for the phosphor substrate. The Macor substrates were coated with a mixture of phosphors suspended in a silica-based colloidal binder. This coating consisted of a 5:1 mixture of lanthanum oxysulfide $\left(\mathrm{La}_{2} \mathrm{O}_{2} \mathrm{~S}\right)$ doped with trivalent europium and zinc cadmium sulfide ( $\left.\mathrm{ZnCdS}\right)$ doped with silver and nickel. The coatings typically do not require refurbishment between runs in the wind tunnel and are approximately 0.001 -in thick. The final step in the fabrication process is to apply fiducial marks along the body to assist in determining spatial locations accurately. The fiducial marks used for the present study were the joints between the Macor inserts, which correspond to the location of the ramp angle changes shown in the sketch in Fig. 7.

The blowing assembly, shown in Fig. 8, was designed to fit within the cavity that held the trip inserts, with consideration of maximizing the internal manifold volume (2.50-in span by 0.750 -in wide by 0.309 -in deep) while accommodating the instrumentation and air-supply lines. Several interchangeable blowing plates representing the external surface of the assembly were replicated and then further machined to provide the various configurations shown in Fig. 6. The span of the internal manifold (or plenum chamber) limited the width of the blowing configurations to approximately 2 -in. The conditions within the plenum were measured with a miniature piezoresistive pressure transducer from Endevco (0-15psia) and a Type E thermocouple with an exposed junction. Pressurized air was provided to the manifold through two supply lines, which were split off a single line through which the total mass flow of the system was measured with various Teledyne Hastings low capacity flow meters. The specific flow meters available for the present study include a HFC-202B with a range up 0.1 standard liters per minute (SLPM), a HFM-200 with a range up to 5 SLPM, and a HFC-203A with a range up to 50 SLPM.

\section{Test Conditions and Data Reduction}

Nominal reservoir stagnation and corresponding freestream flow conditions for the present study are presented in Table 2 (along with HYPULSE conditions from the previous passive study included for reference purposes). Flow conditions for the 20-Inch Mach 6 Air and 31-Inch Mach 10 Air tunnels were calculated based on measured

\begin{tabular}{||c|c|c|c|c|c|c||}
\hline \hline Tunnel & $\mathrm{Re}_{\infty}\left(\mathrm{x} 10^{6} / \mathrm{ft}\right)$ & $\mathrm{M}_{\infty}$ & $\mathrm{P}_{\mathrm{t} 1}(\mathrm{psi})$ & $\mathrm{T}_{\mathrm{t} 1}\left({ }^{\circ} \mathrm{R}\right)$ & $\mathrm{H}_{\mathrm{t} 1}(\mathrm{BTU} / \mathrm{lbm})$ & $\mathrm{P}_{\mathrm{t} 2}(\mathrm{psi})$ \\
\hline 20-In M-6 & 2.2 & 6.0 & 125.5 & 906.6 & 218.2 & 3.8 \\
\hline 31-In M-10 & 2.2 & 9.9 & 1451.7 & 1808.1 & 454.8 & 4.5 \\
\hline HYPULSE & 1.4 & 7.31 & 1994.3 & 3951.0 & 1079.4 & 18.6 \\
\hline
\end{tabular}
reservoir pressures and temperatures and recent unpublished calibrations of the facilities. For the phosphor data, heating rates were calculated from the global surface temperature measurements using the one-dimensional semiinfinite solid heat-conduction equations, as discussed in Ref. 15 and 16. Phosphor system measurement error is a function of the surface

\footnotetext{
${ }^{*}$ Macor is a machinable glass ceramic and is a registered trademark of Corning Incorporated.
} 


\begin{tabular}{||c|c|c|c|c||}
\hline Tunnel or Flight & $\mathrm{M}_{\infty}$ & $\mathrm{Re}_{\infty}\left(\mathrm{x} 10^{6} / \mathrm{ft}\right)$ & $\delta$ (in) & $\mathrm{M}_{\mathrm{e}}$ \\
\hline 20-In Mach 6 & 6.0 & 2.2 & 0.081 & 3.1 \\
\hline 31-In Mach 10 & 9.9 & 2.2 & 0.125 & 4.4 \\
\hline HYPULSE & 7.3 & 1.4 & 0.075 & 4.2 \\
\hline Mach 7 Flight & 7.0 & 0.9 & 0.180 & 3.4 \\
\hline Mach 10 Flight & 10.0 & 0.6 & 0.283 & 4.5 \\
\hline
\end{tabular}

Table 3: Calculated boundary layer parameters at the trip location, $x / L=0.15$.

temperature of the model ${ }^{16}$ and is typically quoted as 8 to $10 \%$ for the 20-Inch Mach 6 tunnel and 7 to $10 \%$ for the 31 Inch Mach 10 tunnel, with overall experimental uncertainty of $\pm 15 \%$. The slightly higher uncertainty for the 20 -Inch Mach 6 is due to the relatively low temperature driver of the facility that results in lower overall surface temperature rise during a typical tunnel run. As will be shown in Fig. 9, a noticeable scatter in the Mach 6 heating images, as compared to similar Mach 10 images is evidence of this increased error. Global heating images are presented in terms of the ratio of heat-transfer coefficients $h / h_{\text {ref, }}$ where $h_{\text {ref }}$ corresponds to the Fay and Ridell ${ }^{24}$ stagnation-point heating on a sphere with radius 4.0-in (a 1/3rd scale 1-ft radius sphere). Repeatability of heat transfer distributions was generally better than $\pm 4 \%$. For the pressure and mass flow data, the millivolt output from the transducers were converted to engineering units based on a recent calibration of the instruments, and the accuracy is typically quoted as $\pm 15 \%$ of full scale.

\section{Discussion of Results}

The Hyper-X forebody model has had several entries into the LAL facilities over the past 7 years producing over 600 runs (see Table 1). Parametrics include the effect of angle-of-attack, Mach number, and Reynolds number for both the passive and active trip configurations with the inlet door simulated in both the open and closed configuration. For the sake of brevity, the present paper provides the wind tunnel cases which most closely match the nominal Mach 7 flight case of $\alpha=2-\mathrm{deg}, \mathrm{Re}_{\mathrm{L}}=5.6$ million with the engine inlet door simulated in the open position. Table 3 provides a comparison of the pertinent parameters in flight to that obtained in the LAL.

\section{A. No Trip Baseline}

Figure 9 is a comparison of the baseline (no trip) results on the Hyper-X forebody between Mach 6 and Mach 10 for the nominal wind tunnel condition of $\alpha=2-\mathrm{deg}$ and $\mathrm{Re}=2.2 \times 10^{6} / \mathrm{ft}$. These results suggest a laminar boundary layer over most of the forebody based on comparisons to laminar computations (see Ref. 1) and the evidence of separations in the oil-flows. These separated flow regions, which appear relatively two-dimensional over the width of the flat ramps, merge with a separated or low shear region, which runs the length of the chines, to generate a chine vortex emanating from the compression ramp corners. Based on the oil-flows, the surface streamlines indicate flow spillage off the flat ramps, with as little as a third of the surface streamlines at the end of the first ramp being captured by the inlet. These results tend to support the earlier concerns regarding flow separations and mass capture. The baseline phosphor heating images have been scaled to fit within a sketch of the model, in order to correctly align the heating results for comparison to the oil-flows. The heating results show the first two ramps to be laminar,

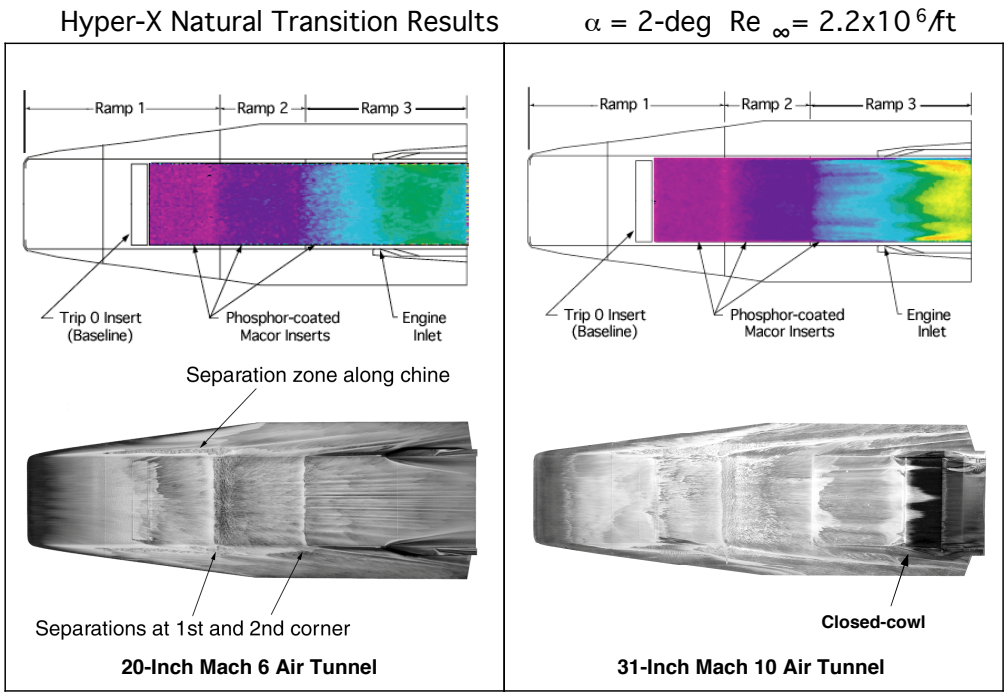

Figure 9. Natural transition results from the Mach 6 and 10 tunnels. with transition onset occurring on the last ramp. As discussed earlier, natural transition onset just prior to the end of the first ramp minimizes flow spillage and provides a turbulent boundary layer for the inlet. Thus, even in the noisy environment of conventional (non-quiet) hypersonic wind tunnels, forced transition via tripping is required at the nominal conditions.

\section{B. Passive Trips}

Figure 10 is a representative comparison of the effect of increased trip height between the passive Trip 1 and $2 \mathrm{c}$ configurations in the 31-Inch Mach 10 Air Tunnel for the nominal condition. As can be seen in the images, the effect of increasing the trip height (k) provides a systematic

8

American Institute of Aeronautics and Astronautics 


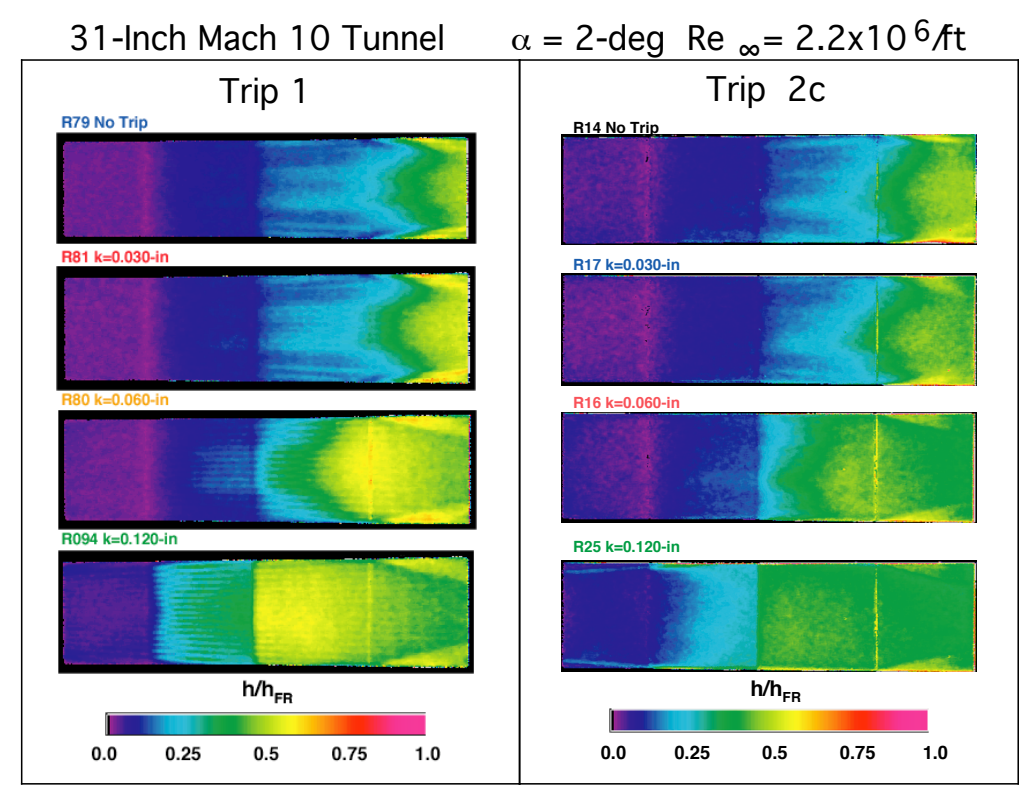

Figure 10. Comparison of passive trip results from the Mach 10 tunnel.

forward movement of the onset of transition from just inside the inlet to the first ramp. For both trips shown in Fig. 10, the height that just begins to affect the location of transition onset, the incipient $\$$ value (using the vernacular from Ref. 25), is $\mathrm{k}=0.030$ in $(\mathrm{k} / \mathrm{\delta}=0.25)$. By $\mathrm{k}=0.060$-in $(\mathrm{k} / \mathrm{\delta}=0.5)$ for both configurations, a significant forward movement of transition (a critical value) onto Ramp 2 is evident. By the largest trip height, $\mathrm{k}=0.120$-in $(\mathrm{k} / \delta=1.0)$, the onset of transition has moved ahead of Ramp 2 for Trip 1, while Trip 2c appears to fall behind slightly. Although the Trip 2c configuration is slightly less effective at promoting transition than Trip 1, the minimization of the organized and persistent vorticity into the turbulent regime is desirable in order to reduce the potential heating to the closed cowl. Based on the images, it does not appear that an effective value has been reached in the Mach 10 tunnel (as transition is not directly behind the trip location), however comparison of the heat transfer distributions to CFD (see Ref. 1) reveal the transition onset is near the trip location for the largest trip.

\section{Active Trips}

For the current active trip study, the passive roughness elements were replaced with the various blowing module assemblies and the internal manifold pressure and total mass flow of the system were systematically varied and

\section{1-Inch Mach 10 Tunnel $\quad \alpha=2$-deg $\operatorname{Re}{ }_{\infty}=2.0 \times 10^{6} / \mathrm{ft}$}

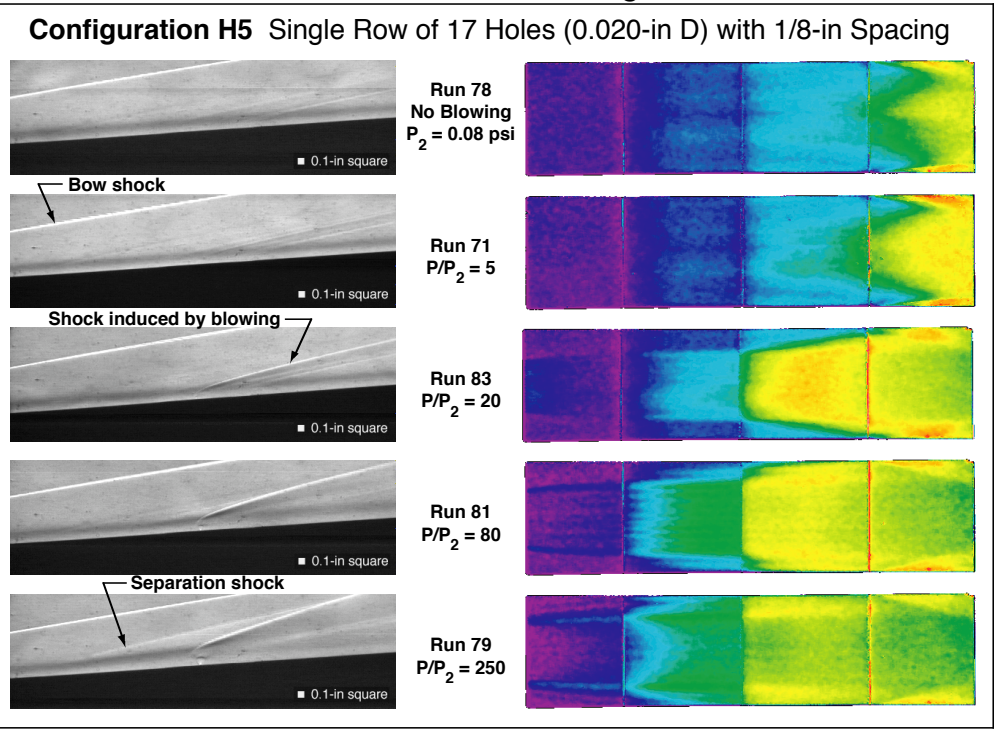

Figure 11. Sample active trip results from Mach 10 tunnel. measured. Figure 11 provides an example of the heating and schlieren results obtained for one configuration, the H5 with a single row of 17 spanwise holes (0.020-in D) spaced 1/8-in apart. The internal pressure transducer was used to monitor the static surface pressure during the no blowing runs and typically measured a value of $\mathrm{P}_{2}=0.08$ psi. Typically, twice the local pressure is required to establish sonic flow through the orifices, however the surface pressure near the holes will be slightly higher due to the induced laminar separation that forms ahead of the jet. Sonic conditions through the holes will ensure that the surface pressure cannot feedback into the manifold.

A manifold pressure of 5 times the static no blowing value produces only slight differences in the schlieren and

\footnotetext{
$\S$ Note that the terminology used here is similar to the definitions of Ref. 25. Incipient identifies the maximum roughness height that has minimal effect on the onset of transition. Critical identifies the roughness height that first begins to move transition rapidly towards the nose. Effective identifies the minimum roughness height that establishes transition onset just downstream of the roughness element.
} 


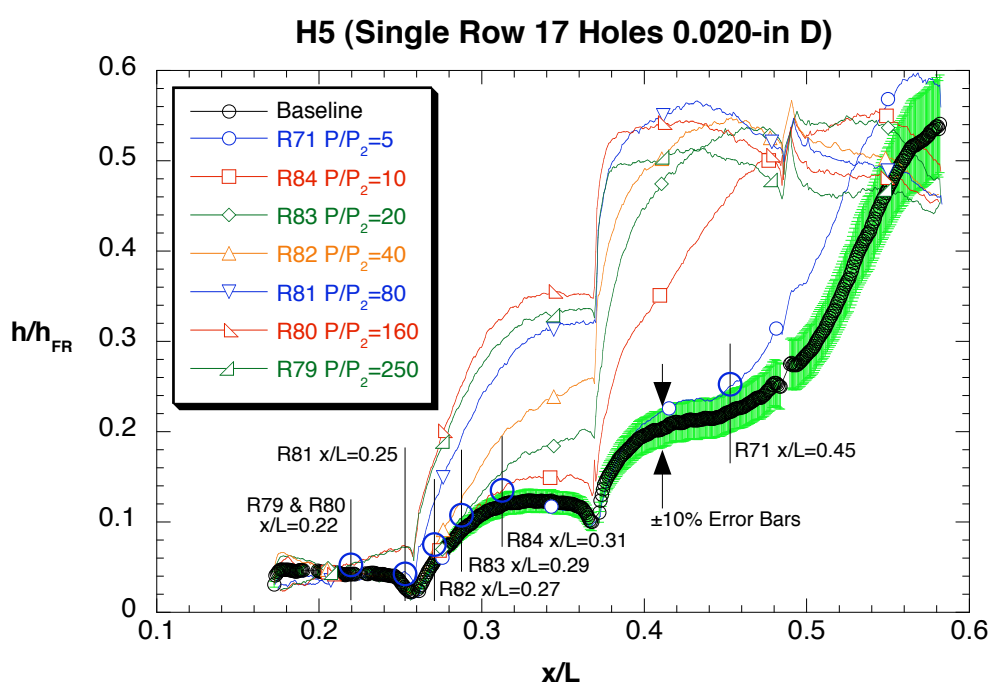

Figure 12. Typical averaged heat transfer distribution for locating transition onset for the Mach 10 data. in the movement of transition. However, as the manifold pressure is increased to roughly 20 times the surface pressure, a greater disturbance is produced in the boundary layer creating a slight shock wave (noted in the schlieren image of Run 83) and transition has progressed forward onto the second ramp. Increasing the manifold pressure to 80 times the static pressure generates an even stronger jet shock and movement of transition to the first ramp. For the highest pressure case shown, $\mathrm{P} / \mathrm{P}_{2}=250$, the jet penetration height is identified in the schlieren (via the Mach disk at the top of the jet) that is approximately the same height as the calculated boundary layer thickness, which moves the jet induced shock further away from the body and forces

the separation region far forward on the model. Note that for this case, transition movement seems to have stabilized just behind the trip location, and in fact the overall heating levels in the turbulent region seems to have been reduced slightly, perhaps an indication of transpiration cooling.

To systematically interpret the transition onset locations, the heating images were used to extract a spanwise array of heating distributions along the streamwise direction, which were then averaged (to minimize scatter) and compared to a baseline (no blowing) case. The transition onset locations were identified by the departure of more than $10 \%$ above the laminar baseline heating distribution, as indicated and marked in Fig. 12. When analyzed in this manner, the onset of transition is evident on Ramp 1 for the highest pressures, although that fact is not obvious by trying to interpret the heating images. The pressure range measured during the present study was adequate for providing the same amount of transition movement observed in the previous passive trip investigation and shown in Fig. 10. For the lowest blowing case, with a manifold pressure of just 5 times the static measurement, the onset of transition appears to move slightly forward of the natural location of $\mathrm{x} / \mathrm{L}=0.5$ (approximately the inlet station) to $\mathrm{x} / \mathrm{L}=0.41$. By doubling the pressure ratio to 10 , transition onset is observed to jump ahead onto the second ramp at $\mathrm{x} / \mathrm{L}=0.31$. Subsequent doublings of the pressure only produces a slight but steady forward movement of transition on the second ramp until a pressure ratio of 80 brings onset to the ramp corner $(\mathrm{x} / \mathrm{L}=0.26)$. By increasing the plenum pressure once again to now 160 times the measured static pressure, transition is seen to jump ahead to the first ramp

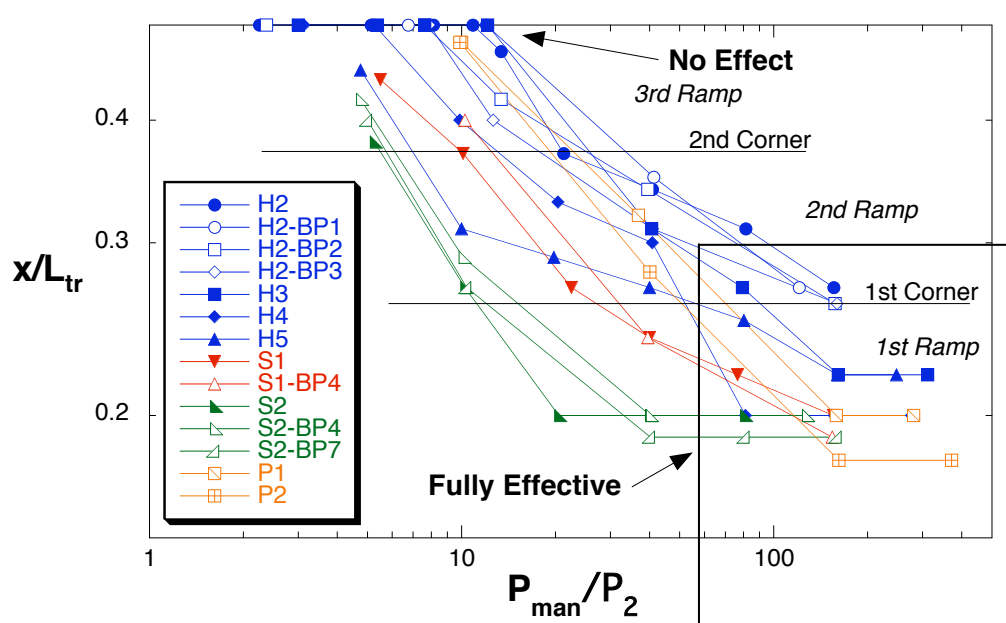

Figure 13. Comparison of transition location as a function of pressure ratio across the surface for all configurations tested. at an $\mathrm{x} / \mathrm{L}=0.22$. No further forward movement of transition is observed past this location as the pressure is increased further. In fact while the size of the jet observed in the schlieren continues to increase as the plenum pressure increases, along with the induced shock and separation, the transition movement is clearly optimized for the $\mathrm{H} 5$ configuration for a manifold pressure of 160 times the measured static pressure. Further increases to the manifold pressure only serve to reduce the measured heating levels as shown in the distributions in Fig. 12 and comparisons of the images of Fig. 11. It is interesting to note that the transition movement is greatly influenced by the ramp corners, with 
onset typically jumping forward close to the next corner region as the tripping effectiveness is increased. How much the discrete ramps affect the actual effectiveness of any given trip configuration is unclear and may warrant further investigation.

Based on the Ames compressible flow tables the minimum pressure ratio $\left(\mathrm{P} / \mathrm{P}_{2}\right)$ across the surface that is required to establish sonic flow through the orifices is 1.89 . The flow separation ahead of the holes (see Fig. 4) would increase the local pressure and thus the manifold pressure required for sonic flow. For laminar conditions, jet induced flow separations would augment the local pressure by a factor of roughly 2 or more. ${ }^{26}$ Since the measured $\mathrm{P}_{2}$ condition is based on the no blowing measurements (and no separation), the rough rule of thumb used here is that a $\mathrm{P} / \mathrm{P}_{2}$ on the order 4 would be required for sonic conditions within the holes or slots. For pressure ratios above this value, the sonic jets would expand farther out into the boundary layer increasing the jet penetration height and separation regions. Figure 13 shows the present results from the 31-Inch Mach 10 Tunnel for measured transition onset as a function of the plenum-to-static pressure ratio for all configurations tested, indicating that typically a manifold pressure of 5 times the surface static pressure is required to move the transition point appreciably away from the natural position of $\mathrm{x} / \mathrm{L}=0.5$. Based on the schlieren results shown in Fig. $11, \mathrm{P} / \mathrm{P}_{2}=5$ produces just enough of a disturbance in the boundary layer to establish a very subtle shock emanating from the jet, which would suggest that the Mach disk is very close to the wall. To get significant movement of transition to nearly the effective point (at or near the trip location), a pressure ratio on the order of 10 times the sonic limit (approximately $\mathrm{P} / \mathrm{P}_{2}=40$ ) is required.

As can be seen in Fig. 13, the best performer, in terms of the most transition movement for the lowest pressure were the saw tooth configurations. The S2 configurations, both with and without the backing plates to block off sections of the saw tooth slot, was able to get nearly effective movement of transition for pressure ratios of approximately 20 to 40 . The next best in terms of effectiveness was configuration $\mathrm{H} 4$, a triple row of 50 (total) 0.010 -in holes, spaced 1/8-in apart, which initially lagged behind the $\mathrm{H} 5$ configuration for lower pressures but then became more effective at the higher pressures. Next, the straight slot configurations had systematic forward movement of transition that approached the effective limit at a pressure ratio near 100. Surprisingly, the addition of the BP4 backing plate to the S1 did not affect the results significantly. Conventional wisdom would suggest that the straight slot would generate a two-dimensional disturbance that would be far less effective at promoting transition and the backing plates were intended to introduce three-dimensionality to this configuration. The porous configurations, P1 and P2, were able to achieve effective tripping for a pressure ratio of 160 . Interestingly, the better performers shown in Fig. 13 correspond to the configurations that had the larger total exit areas and thus higher mass flow. Similar performance trends as a function of pressure ratio were observed in the Mach 6 tunnel.

Figure 14 provides the present Mach 10 results for transition onset locations, but now as a function of the measured total mass flow for all the configurations tested. Plotted in this fashion, the results show a little less spread, but with different conclusions as to the better trip performer. In terms of most transition movement for the lowest total mass flow, the $\mathrm{H} 2$ with backing plates seemed best. The backing plates essentially block off sets of holes thereby reducing the total exit area and thus reducing the mass flow for a given pressure ratio. However, the increased spacing between open holes allows for less uniform transition fronts, which presumably would be a concern for applications where flow uniformity is an issue (such as within scramjet inlets). Another way to interpret

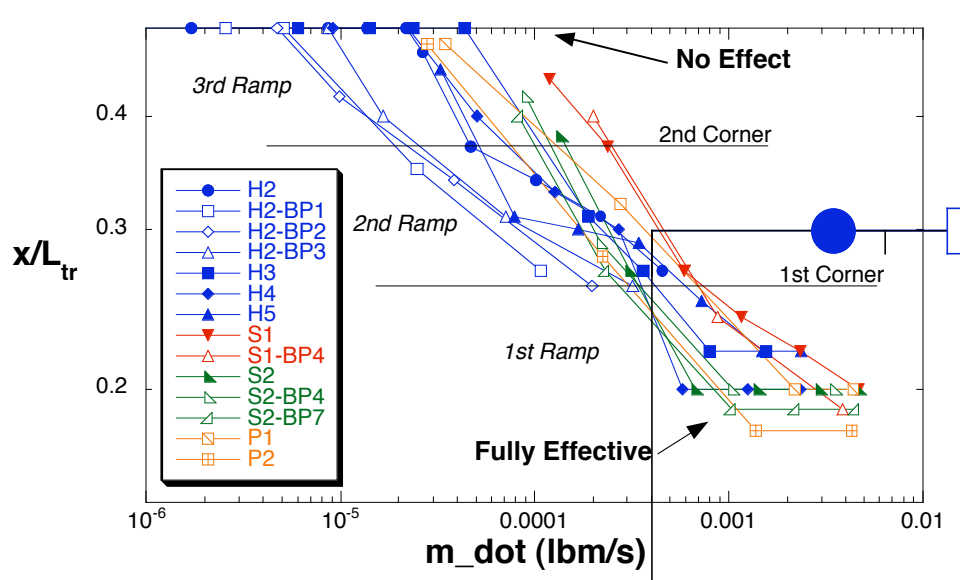

Figure 14. Comparison of transition location as a function of total mass flow for all configurations tested. the results shown in Fig. 14 is that for a given mass flow rate the configurations with the highest manifold pressure (i.e. those with blocked holes) performed better. Clearly, there is interdependency between the total mass flow and pressure which is not obvious when trying to interpret the results shown in Figs. 13 and 14.

For sonic conditions at the throat of the orifices, the mass flow is essentially a function of the manifold pressure and the throat area (assuming the local conditions are held constant). Figure 15 presents the measured mass flow per unit area as a function of manifold pressure for the holes only. 


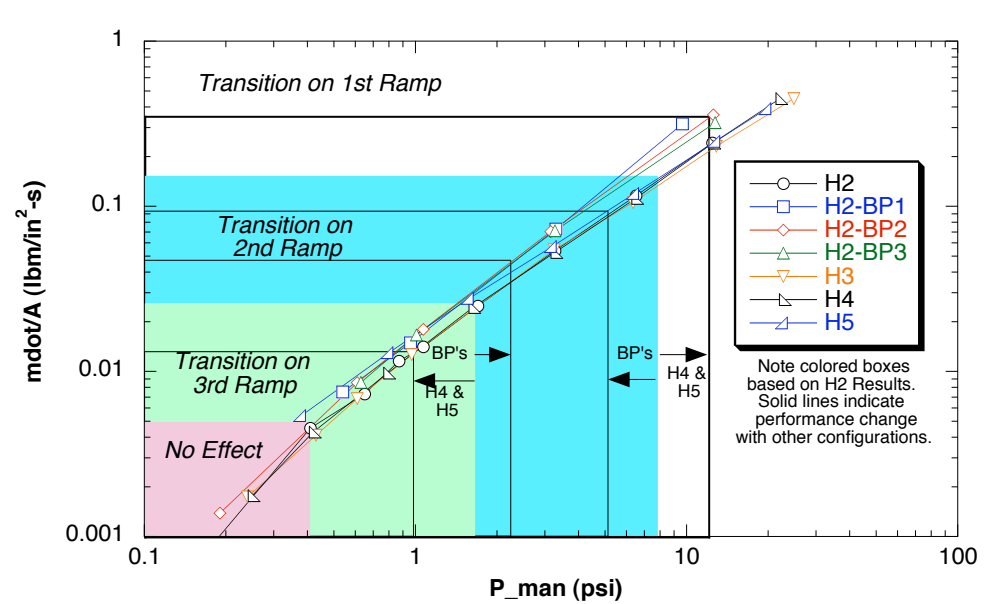

Figure 15. Transition location as a function of total mass flow per unit area and manifold pressure for holes.
Indeed, when plotted in this manner, one can see the straight-line dependency between pressure and mass flow. The area used to convert the measured total mass flow to a unit mass flow (per unit area) was a summation of area of all the holes based on actual measured hole diameters determined with precision hole gauges. The four configurations without backing plates essentially collapse to a single linear function. The only exceptions are the results from the configurations utilizing the backing plates. The backing plates were assumed to provide complete sealing of the blocked holes. The manifold assembly was designed with

an o-ring to insure proper sealing, however the backing plates were not. Perhaps the effective area associated with the backing plate configurations is a bit higher than assumed due to the potential for leaking through the blocked holes.

Also plotted on Fig. 15 is a qualitative assessment of the transition onset location relative to the H2 results. The colored boxes indicate the specific mass flow per unit area and pressure required for the $\mathrm{H} 2$ configuration to move transition onset from no effect (red) forward on the third ramp (green) and on to the second (blue) and first (white) ramps. Relative to the $\mathrm{H} 2$ results, the backing plate configurations required higher pressures and unit mass flow to provide the same level of transition movement, while the H4 (triple row of 0.010-in holes) and H5 required less. The $\mathrm{H} 3$ (double row of 0.010-in holes) results were similar to the $\mathrm{H} 2$ trends.

Figure 16 provides the corresponding results for the slot and porous configurations. The S1 and S2 cases (without backing plates) exactly matched the linear response curve shown in Fig. 15 for the holes. The total area used for S1 and S2 was based on measured slot dimensions as determined with precision feeler gauges and calipers. The slotted cases with backing plates also behaved similar to the results for holes with backing plates, which may suggest that backing plates may have to be redesigned with some method for sealing off additional leak paths. Or perhaps the backing plates can be calibrated to determine an effective area that accounts for the lack of a seal. For the porous configurations (P1 and P2), no area measurements were possible, so for this plot an area was assumed that brought the unit mass flow curve in line with the other configurations for the higher pressures. The porous results shown are qualitative in nature and will have to be corrected using an "effective" area based on calibrated results. The lack of a linear response, however, with the porous configurations may indicate that the effective areas for porous mediums are likely dependent on the pressure difference across the surface. Also shown in Fig. 16 is the

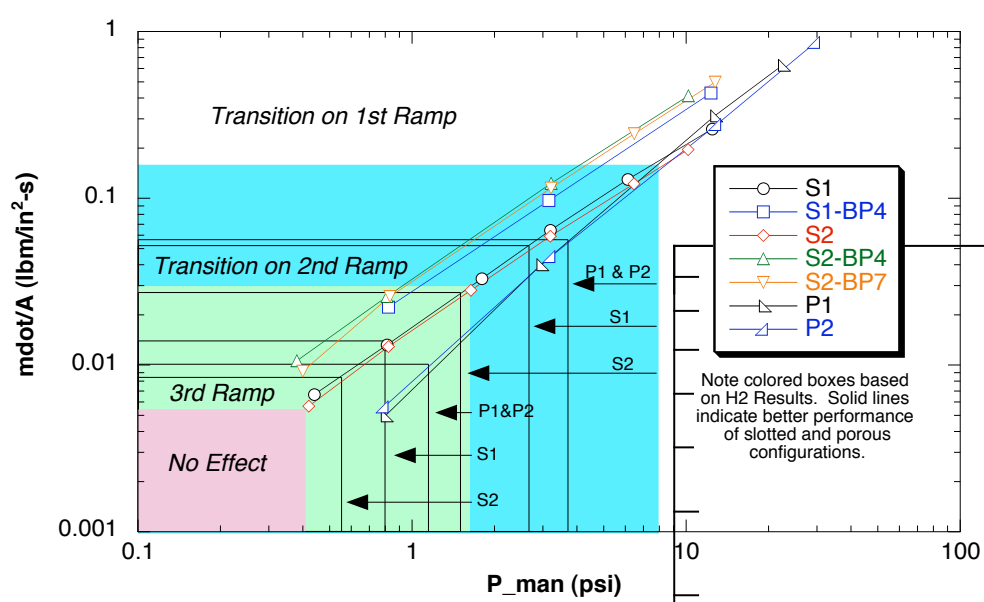

Figure 16. Transition location as a function of total mass flow per unit area and manifold pressure for slot and porous configurations. relative assessment of the transition results. All the configurations shown here performed better than the $\mathrm{H} 2$ results, with the saw-tooth slot (S2) having the best forward movement of transition for the lowest combination of pressure and unit mass flow. The S2 was able to move transition onset onto the $1^{\text {st }}$ ramp (the design criteria for the Hyper-X Mach 7 flight) for manifold pressure of $1.6 \mathrm{psi}\left(\mathrm{P}_{\operatorname{man}} / \mathrm{P}_{2}=20\right)$ and total mass flow of $0.00068 \mathrm{lbm} / \mathrm{s}$ $\left(\mathrm{m}-\operatorname{dot} / \mathrm{A}=0.028 \mathrm{lbm} / \mathrm{in}^{2}-\mathrm{s}\right)$. These results seem encouraging enough to consider initiating a trade study of system and control requirements for determination of the feasibility of use on future hypersonic flight

12

American Institute of Aeronautics and Astronautics 


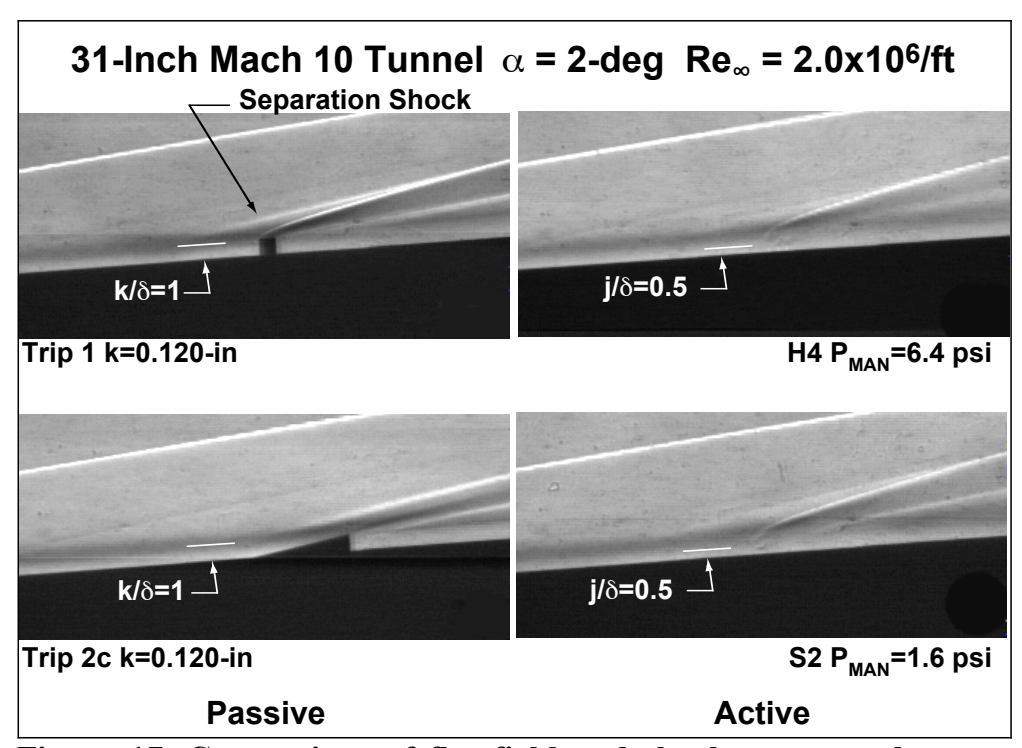

Figure 17. Comparison of flowfield and shock structure between passive and active trips for effective results.

applications. The benefit of a boundary layer control system with increased flexibility would have to be weighed against the impact of the added complexity from additional tanking, piping, and control systems.

Figure 17 provides a comparison of the shock system around both passive and active trip configurations for representative cases in which the heating results indicated that the transition onset results were nearly effective. The two passive trip results represent the same cases shown earlier, the Trip 1 and 2c configurations for the largest trip height, $\mathrm{k}=0.120$-in. The calculated boundary layer thickness for the wind tunnel conditions shown was $\delta=$ 0.125 -in, shown in Table 3. The observed boundary layer edge from the schlieren images, as interpreted by the darker band above the surface, essentially matches the trip height. The two active trip cases shown correspond to the best performers, the S2 and H4 configurations, for the minimum pressure ratios required to obtain effective tripping, $\mathrm{P} / \mathrm{P}_{2}$ of 20 and 80 , respectively. The observed jet penetration height for both active examples was smaller than the boundary layer edge, roughly a $j / \delta$ of 0.5 for both, along with smaller jet shock and flow separations than the passive cases. As had been previously cited in Ref. 11, the jet penetration height alone does not appear to be directly analogous to passive trip heights. The current results would suggest that a multiplier of twice the jet penetration height is more appropriate for equating the active results to passive.

\section{Conclusion}

An experimental investigation of boundary layer trip effectiveness on a 33\% scale Hyper-X forebody model has been conducted in the 20-Inch Mach 6 Air Tunnel and the 31-Inch Mach 10 Air Tunnel. These facilities provided a range of Mach number and length Reynolds number to simulate Hyper-X Mach 7 flight conditions. Phosphor thermography was used to provide heat transfer images and distributions, which were used to monitor the movement of transition onset locations for a variety of active and passive boundary layer tripping elements. The aeroheating results were complemented with oil-flow images that provided surface streamline information and schlieren images that provided shock system details. The passive trip results were previously used to select a final trip configuration and height for the Hyper-X Mach 7 flight vehicle, which now has been successfully flown.

For the most recent experimental study, fourteen blowing configurations were screened and the results indicated that all were adequate for providing transition onset movement. Pressure ratios across the model surface as low as 5 , which barely ensures that sonic conditions are maintained through the minimum area, or throat, were adequate for moving transition away from the natural transition location. To move transition onset to the trip location, thereby providing an effective trip, pressure ratios of 40 or higher were required. The saw tooth slot (S2) provided the most effective movement of transition for the smallest pressure ratio across the model surface, while the H4 configuration (with the larger hole diameter arraigned in a single row) was the best of the round hole concepts. The current results suggest that active methods for boundary layer control on hypersonic airbreathing vehicles seem feasible and that a trade study of system and control requirements is warranted.

\section{Acknowledgments}

This experimental effort was accomplished with the help of many dedicated individuals, a few of which are mentioned here. The model was built with the help of William Kimmel, Kevin Meidinger, Greg Draughon, Mike Powers, Mark Griffith, and Jim Bartlett. Mark also came to the rescue with his assistance in quickly repairing the model during a recent tunnel entry. The LAL testing was accomplished with the support of Paul Tucker, Johnny 
Ellis, Rhonda Murphy, Henry Fitzgerald, Tony Robbins, Grace Gleason, Bert Senter, Kevin Hollingsworth, Glenn Bittner, and Ron Merski.

\section{References}

\footnotetext{
${ }^{1}$ Berry, S. A., Auslender, A, H., Dilley, A. D., and Calleja, J. F., "Hypersonic Boundary Layer Trip Development for HyperX,” J. Spacecr. Rockets, Vol. 38, No. 6, pp. 853-864, 2001.

${ }^{2}$ Berry, S. A., DiFulvio, M., and Kowalkowski, M. K.,. "Forced Boundary Layer Transition on X-43 (Hyper-X) in NASA LaRC 31-Inch Mach 10 Air Tunnel," NASA/TM-2000-210315, 2000.

${ }^{3}$ Berry, S. A., DiFulvio, M., and Kowalkowski, M. K., "Forced Boundary Layer Transition on X-43 (Hyper-X) in NASA LaRC 20-Inch Mach 6 Air Tunnel,” NASA/TM-2000-210316, 2000.

${ }^{4}$ Calleja, J. F., "Boundary Layer Transition Experiments on a One-Third Scale Hyper-X Forebody Model at Mach 7 and 10 ," GASL Technical Report No. 382, 2000.

${ }^{5}$ Rausch, V. L., McClinton, C. R., and Crawford, J. L., "Hyper-X: Flight Validation of Hypersonic Airbreathing Technology," ISABE Paper 97-7024, 1997.

${ }^{6}$ Rausch, V. L., McClinton, C. R., and Hicks, J. W., "NASA Scramjet Flights to Breath New Life into Hypersonics." Aerospace America, Vol. 35, No. 7, pp. 40-46, 1997.

${ }^{7}$ McClinton, C. R., Holland, S. D., Rock, K. E., Englund, W. C., Voland, R. T., Huebner, L. D., and Rogers, R. C., "Hyper-X Wind Tunnel Program," AIAA Paper 98-0553, 1998.

${ }^{8}$ Lau, K. Y., and Vaporean, C. N., "Parametric Boundary Layer Transition Study for NASP-like Configuration Using Linear Stability Analyses," Presented at the National Aerospace Plane Mid-term Technology Review, Monterey CA, paper number 283, 1992.

${ }^{9}$ Dilley, A. D., "Hyper-X Trip Sizing and Preliminary Drag Estimates,” Hyper-X Technical Note 96HN0064, NAS1-19864, 1996.

${ }^{10}$ Stetson, K. F., Thompson, E. R., Donaldson, J. C., and Siler, L.G., "Laminar Boundary Layer Stability Experiments on a Cone at Mach 8, Part 2: Blunt Cone," AIAA Paper 84-0006, 1984.

${ }^{11}$ Stone, D. R., and Cary, A. M., "Discrete Sonic Jets Used as Boundary-Layer Trips at Mach Numbers of 6 and 8.5," NASA TN D-6802, 1972.

${ }^{12}$ Miller, C. G., "Langley Hypersonic Aerodynamic/Aerothermodynamic Testing Capabilities - Present and Future," AIAA Paper 90-1376, 1990.

${ }^{13}$ Micol, J. R., "Langley Aerothermodynamic Facilities Complex: Enhancements and Testing Capabilities," AIAA Paper 980147, 1998.

${ }^{14}$ Buck, G. M., “Automated Thermal Mapping Techniques Using Chromatic Image Analysis,” NASA TM 101554, 1989.

${ }^{15}$ Buck, G. M., "Surface Temperature/Heat Transfer Measurement Using A Quantitative Phosphor Thermography System," AIAA Paper 91-0064, 1991.

${ }^{16}$ Merski, N. R., "Reduction and Analysis of Phosphor Thermography Data with the IHEAT Software Package," AIAA Paper 98-0712, 1998.

${ }^{17}$ Horvath, T. J., Berry, S. A., Merski, N. R., and Fitzgerald, S. M., "X-38 Experimental Aerothermodynamics," AIAA Paper 2000-2685, 2000.

${ }^{18}$ Berry, S. A., Horvath, T. J., Roback, V. E., and Williams, G. B., "Results of Aerothermodynamic and Boundary-Layer Transition Testing of 0.0362-Scale X-38 (Rev. 3.1) Vehicle in NASA Langley 20-Inch Mach 6 Tunnel," NASA TM-112857, 1997.

${ }^{19}$ Berry, S. A., Horvath, T. J., DiFulvio, M., Glass, C., Merski, N. R., "X-34 Experimental Aeroheating at Mach 6 and 10 ,” J. Spacecr. Rockets, Vol. 36, No. 2, pp. 171-178, 1999.

${ }^{20}$ Berry, S. A., Horvath, T. J., Hollis, B. R., Thompson, R. A., and Hamilton, H. H., "X-33 Hypersonic Boundary Layer Transition," AIAA Paper 99-3560, 1999.

${ }^{21}$ Hollis, B. R., Horvath, T. J., Berry, S. A., Hamilton, H. H., and Alter, S. A., "X-33 Computational Aeroheating Predictions and Comparisons with Experimental Data," AIAA Paper 99-3559, 1999.

${ }^{22}$ Loomis, M. P., Venkatapathy, E., Davies, C. B., Campbell, C. H., Berry, S. A., Horvath, T. J., and Merski, N. R., "Aerothermal CFD Validation and Prediction for the X-38 Program," AIAA Paper 97-2484, 1997.

${ }^{23}$ Hamilton, H. H., Berry, S. A., Horvath, T. J., Weilmuenster, K. J., "Computational/ Experimental Aeroheating Predictions for X-33 Phase II Vehicle,” AIAA Paper 98-0869, 1998.

${ }^{24}$ Fay, J. A., and Ridell, F.R., "Theory of Stagnation Point Heat Transfer in Dissociated Air," J. Aerosp. Sci,. Vol. 25, No. 2, pp. 73-85,121, 1958.

${ }^{25}$ Bertin, J. J., Hayden, T. E., and Goodrich, W. D., "Shuttle Boundary-Layer Transition Due to Distributed Roughness and Surface Cooling,” J. Spacecr. Rockets, Vol. 19, No. 5, pp. 389-396, 1982.

${ }^{26}$ Spaid, F. W., and Cassel, L. A., “Aerodynamic Interference Induced by Reaction Controls,” AGARD-AG-173, 1973.
} 